\title{
Reconstruction of GABAergic Transmission and Behavior by Striatal Cell Grafts in Rats with Ischemic Infarcts in the Middle Cerebral Artery
}

\author{
Hitoo Nishino', Noritaka Aihura², András Czurko ${ }^{1,3}$, Takeshi Hashitani1, Yoshiaki Isobe ${ }^{1}$, Osamu Ichikawa ${ }^{4}$ \\ and Hiroshi Watari ${ }^{4}$ \\ Departments of 1 Physiology and -Neurosurgery, Nagoya City University Medical School, Mizuko-ku, Nagoya \\ 467, Japan, \\ 3Institute of Physiology, Pecs Medical School, Pecs H-7643, Hungary and ${ }^{4}$ National Institute for \\ Physiological Sciences, Okazaki 444, Japan
}

\section{SUMMARY}

Fetal striatal cell suspensions were grafted stereotaxically into the infarcted striatum of rats, and reconstruction of striatcpsillidal GABA transmission and behavior wice investigated. Occlusion of the middle cerebral artery (MCA) for one hour induced ischemic infarcts mainly in the lateral striatum, as detected by magnetic resonance imaging (MRI) and histology. Ischemic rats had deficits in the performance of a passive avoidance task, both acquisition and retention, but no changes in general circadian actograms. In these animals pallidal GABA, detected by microdialysis, decreased to about half of control levels. There were suggestions of an improvement in passive avoidance performance in the grafted animals. Pallidal GABA concentrations recovered almost to control levels, and were increased by infusions of the GABA uptake blocker nipecotic acid. These data indicate that neural transplantation is a promising approach to improve the deficits in chemical transmission and behavior following ischemic infarcts in rat striatum.

\section{KEY WORDS}

ischemia, middle cerebral artery, striatum, transplantation, GABA, passive avoidance

Reprint address:

H. Nishino

Department of Physiology

Nagoya City University Medical School

Mizuho-ku, Nagoya 467, Japan

\section{INTRODUCTION}

In experimental animals, disturbed brain function in various model diseases can be improved by neural grafting. Among these, neural transplantation in animal models of Parkinson's disease is one of the best examples $/ 1,16 /$. Brain ischemia and infarcts are very frequent events that induce severe behavioral and cognitive impairments and are sometimes fatal. There are, however, only a few reports that deal with functional recovery after grafting of neuronal cells in ischemia models $/ 8,9,15,17 /$. The aim of the present study is to further investigate neural grafting in the restoration of brain function following ischemic brain injury.

Several ischemia models are currently in use. Among these, a total ischemic model produced by occlusion of four vessels $/ 19 /$ and a local ischemic model produced by occlusion of a specific vessel $17 /$ are the most widely used. In the present study, in rats, we first occluded the middle cerebral artery for one hour to induce ischemic infarcts in the lateral part of the striatum and adjacent cortex. Deficits in behavior and GABAergic transmission were then investigated following grafting of fetal striatal cell suspensions into the infarcted striatum.

\section{MATERIALS AND METHODS}

Animals

Wistar male rats weighing 250 to $300 \mathrm{~g}$ at the start of the experiment were used. They were divided into 3 groups: control $(\mathrm{n}=6)$, ischemic $(n=12)$ and ischemia-grafted (grafted, $n=4)$, and 
housed in ordinary acrylic cages with food and water provided ad libitum. The room temperature was $25 \pm 1^{\circ} \mathrm{C}$ with a $12 \mathrm{~h}$ light-dark cycle (light 0500 to 1700 , dark 1700 to $0500 \mathrm{~h}$ ).

\section{Ischemia}

Under $2 \%$ halothane anesthesia, the right common carotid artery was ligated, then a 4.0 nylon surgical thread with a $24 \mathrm{G}$ dental rubber plug on the tip was inserted intraluminally, from the right external carotid artery to the circle of Willis via the internal carotid artery. The plug was held on when resistance was felt during the insertion, and was set at the origin of the right MCA, about 12 to $13 \mathrm{~mm}$ from the carotid bifurcation as previously described /7,10,22/ (Figs. $1,2 \mathrm{~A})$. Anesthesia was then terminated and the rats were allowed to move about freely. After one hour occlusion of the MCA, the animal was again anesthetized by halothane, the plug was pulled out, the ligation of the common carotid artery was removed, and the circulation to the right MCA was restored.

\section{MRI}

One and a half months after the ischemia the location and the extent of the infarcts due to the ischemia were detected noninvasively by MRI (Hitachi) (Fig. 1). Under pentobarbital anesthesia the head of the rat was fixed in a $5 \mathrm{~cm}$ coil which was set at the center of the magnetic core (static magnetic field, 2.1 tesla). Spin was raised for 15 to $17 \mathrm{~min}$ and the reflecting radio wave was detected. The spatial resolution was $256 \times 256$ pixels, with one pixel measuring 200 by $200 \mu \mathrm{m}$.

\section{Circadian actogram}

To investigate the variation in general activity following ischemia, circadian actograms in 6 control and 6 ischemic rats were measured for 6 consecutive days using Animex activity monitors during 2 to 3 months following ischemia (Fig. 1).

\section{Passive avoidance task}

Rats were trained in a passive avoidance task for 5 min every day for 6 consecutive days. They were first placed on a small wooden escape platform in an acrylic box $(38 \mathrm{~cm} \times 38 \mathrm{~cm}$ ) equipped with an electric grid floor. At $5 \mathrm{sec}$ after the rats stepped down to the grid, an alternating current $(\sim 1 \mathrm{~mA})$ was passed for $25 \mathrm{sec}$ to give an electric stimulation (ES) /6/. Rats could avoid the ES by stepping up onto the platform. If they did not step up onto the platform the ES was shut off after $25 \mathrm{sec}$, and the animals were placed again on the platform. The total duration (time) of ES rats received during the $5 \mathrm{~min}$ test was recorded and used as a measure of performance. The first series of passive avoidance tasks was initiated one month after ischemia, the second after 2 months, the third series 3 months after ischemia and one month after transplantation, and the fourth series was initiated 6 months after ischemia and 4 months after transplantation (Fig. 1).

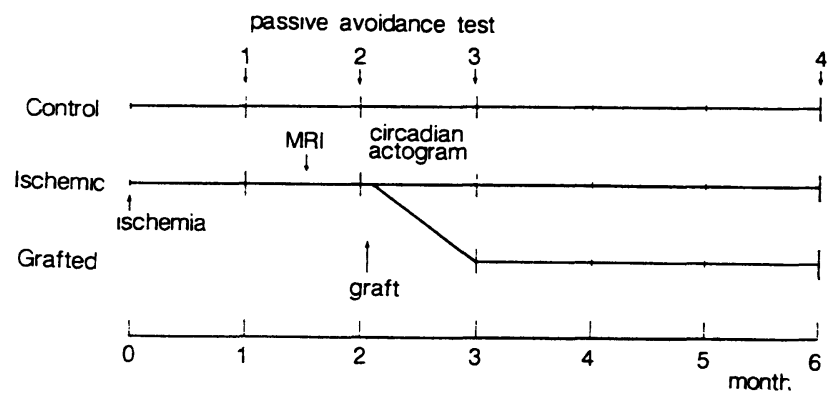

Fig. 1: Experimental design. Rats were first divided into control and ischemic groups. Ischemia was induced by intraluminal occlusion of the MCA. Control rats were left intact. Passive avoidance was tested 4 times (6 sessions each), 1, 2, 3 and 6 months after the ischemia. The extent of the ischemia was monitored by MRI at one and a half months after the ischemia. Circadian actograms were recorded during 2 to 3 months. After the second series of passive avoidance tests, neural transplantation was introduced to one third of ischemic rats.

\section{Neural transplantation}

Four ischemic rats received transplants 2 months after ischemia (Fig. 1). Under pentobarbital anesthesia fetuses were collected from pregnant mothers (gestational days 15 to 16) of the same strain. Brains were removed and pooled in cold 
$0.6 \%$ glucose-saline. Striatal tissues were dissected out and pooled in the same medium. Single cell suspensions (approximately $2 \times 10^{7}$ cells $/ \mathrm{ml}$ ) were made by gentle trituration of the tissue after trypsinization $(0.05 \%$, Sigma type II) for $30 \mathrm{~min}$ at $37^{\circ} \mathrm{C} / 13 /$. Under pentobarbital anesthesia $15 \mu \mathrm{l}$ of the cell suspensions (approximately 300,000 cells) were grafted into the striatum along a vertical tract, with $5 \mu \mathrm{l}$ placed in each of 3 different sites (A: 7.0 to $9.0 \mathrm{~mm}, \mathrm{~L}: 2.0$ to $4.5 \mathrm{~mm}, \mathrm{~V}: 5.0,4.5,4.0 \mathrm{~mm}$ from the surface), and another $6 \mu l$ (approximately 120,000 cells) were grafted along an oblique track, with $2 \mu \mathrm{l}$ in each of 3 sites to make a bridge between the striatum and pallidum (Fig. 2B).
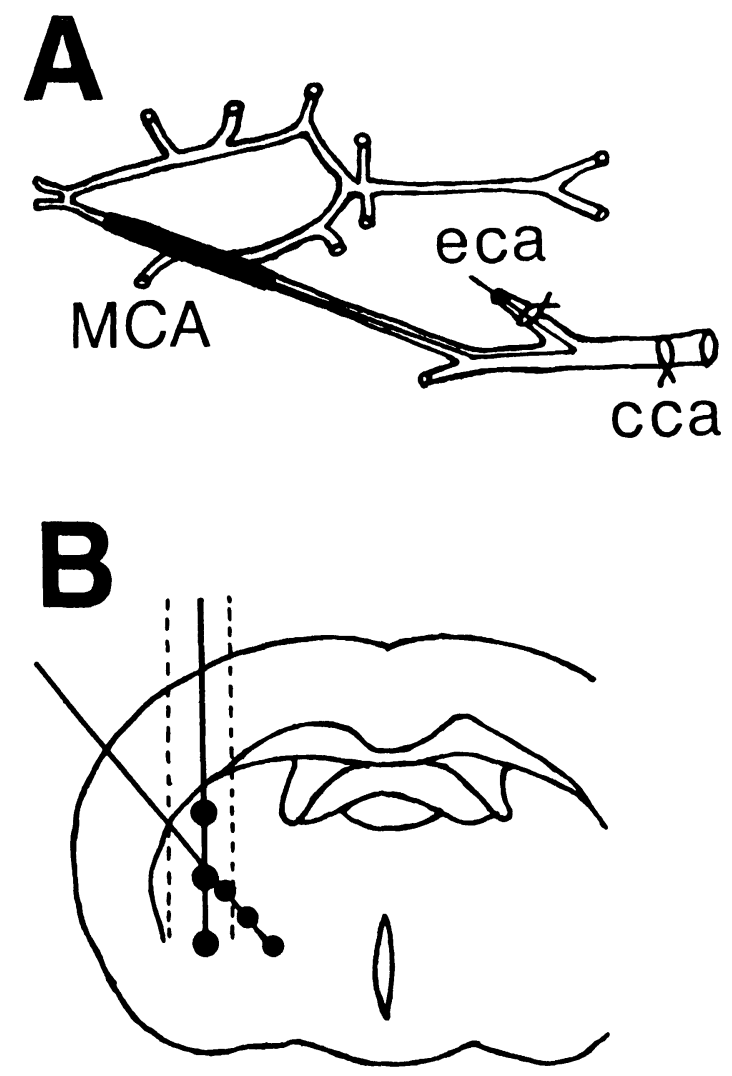

Fig. 2: Ischemia (A) and neural transplantation (B). A. Under halothane anesthesia a plug with nylon surgical thread was inserted from the right external carotid artery (eca) to the circle of Willis and set at the origin of the right MCA for one hour. cca, common carotid artery. B. 2 months after the ischemia, fetal striatal cells were grafted into the infarcted striatum in 6 different sites: 3 using vertical and the other 3 using oblique coordinates.
Control rats were left intact (totally naive) and ischemic rats received the same stereotaxic insertions but no graft of suspension vehicle or cells.

\section{Microdialysis}

A microdialysis probe was inserted into the pallidum of ischemic rats during 2 to 4 months after ischemia and of grafted rats at 4 months after grafts, and dialysates were collected to assay the extracellular content of GABA, the transmitter in the striatopallidal pathway $/ 20 /$. Microdialysis was also performed in intact control rats. Ringer's solution was perfused at a constant rate of $1 \mu \mathrm{l} / \mathrm{min}$ in the probe, the tip of which was covered by cellulose acetate tubing ( $2 \mathrm{~mm}$ long, $0.25 \mathrm{~mm}$ diameter, mol. cut-off 5,000 , recovery rate $20 \%$ ) /13/. After 3 hours of preperfusion dialysates were collected every $30 \mathrm{~min}$ for 3 hours. To examine the dynamics of GABA turnover at the terminal, GABA uptake blocker (nipecotic acid, $2 \mathrm{mM}$ ) /5/ was added to the Ringer's solution. The samples were pretreated with $10 \mu \mathrm{l}$ of $4 \mathrm{mM}$ Ophtalaldehyde (OPA) for $2.5 \mathrm{~min}$ before the assay 14/. GABA was assayed by high performance liquid chromatography (HPLC, EICOM PAK, MA-50DS) with electrochemical detection (EICOM, ECD-100) by retention time of 20 to $22 \mathrm{~min}$. The mobile phase consisted of $0.05 \mathrm{M}$ phosphate buffered saline (55\%) and $45 \%$ methanol, at $\mathrm{pH} 3.5$.

\section{Histology}

Under deep anesthesia rats were perfused transcardially with physiological saline and fixative (4\% paraformaldehyde in $0.1 \mathrm{M}$ phosphate buffer), and brains were removed. Frozen $40 \mu \mathrm{m}$ sections were stained with cresyl violet.

\section{RESULTS}

\section{General behavior and actograms}

When the halothane anesthesia was cut off, rats showed left hemiparesis and turned to the left during the occlusion of the right MCA. However, hemiparesis disappeared in a few days and thereafter no apparent disturbances were observed 
in freely moving animals. Some ischemic rats showed slightly increased motor activity at night, and some showed decreased activity, but overall there were no significant variations in the circadian actograms (Fig. 3).
$! 1$

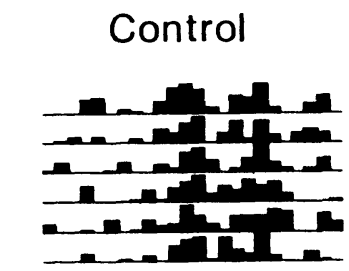

2

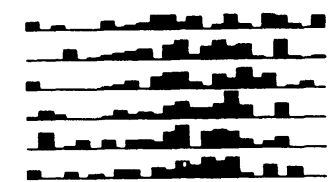

3

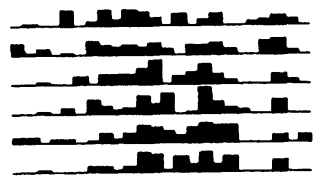

4

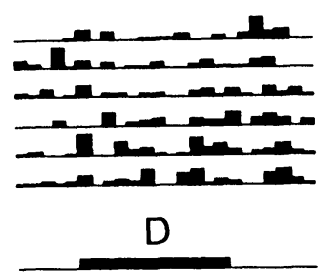

Ischemic

5

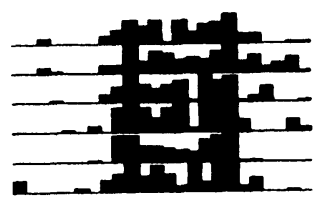

6

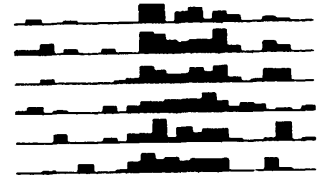

7

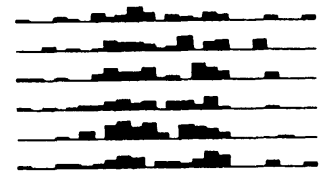

8

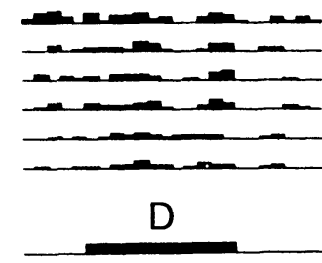

Fig. 3: Circadian actograms of control (\#1 to 4) and ischemic (\#5 to 8) rats. Actograms were made by accumulating the count of activity every hour for 6 consecutive days. L, 0500-1700; D, 1700-0500. Rat \#5 showed a slightly increased activity at night, but the majority showed no significant variations in circadian actograms after the ischemia. Rats \#4 and 8 showed no apparent circadian rhythm.

\section{Estimation of the infarcts by MRI}

The location and the size of the infarcts were detected noninvasively by MRI before transplantation. Fig. 4 shows examples of MRI pictures. Infarcts were located mainly in the lateral half of the striatum and lateral cortex, but their location and size were somewhat variable.
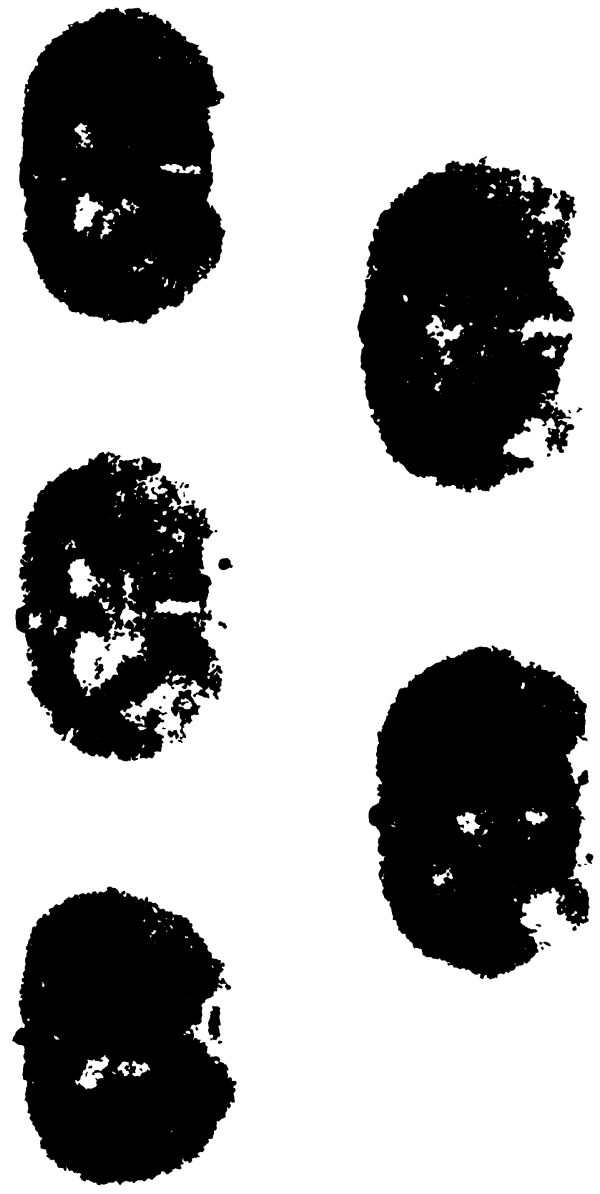

Fig. 4: MRI pictures of the frontal section of the brain in 5 ischemic rats. Spin echo $T_{1}$ images were made under 2.1 tesla magnetic field. Resolution, $256 \mathrm{x}$ 256 pixels with 200 by $200 \mu \mathrm{m}$. Infarcts were located mainly in the lateral striatum and adjacent cortex.

\section{Passive avoidance task}

On the first day of the first training session, rats often stepped down to the floor grid and received much ES; thus, the total time of ES was to 60 to 80 $\mathrm{sec}$ in the first $5 \mathrm{~min}$ test (Fig. 5A). The total time of ES decreased with training (One factor ANOVA for repeated measures, Fisher PLSD 13.108, p<0.05: day 1 vs day 2 to 6 , day 2 vs. day 3 to 6 ). In control rats, the duration of ES remained at only 5 to $10 \mathrm{sec}$ after 6 days of training. Although there was no significant difference in the time course of acquisition between control and ischemic rats (2- 

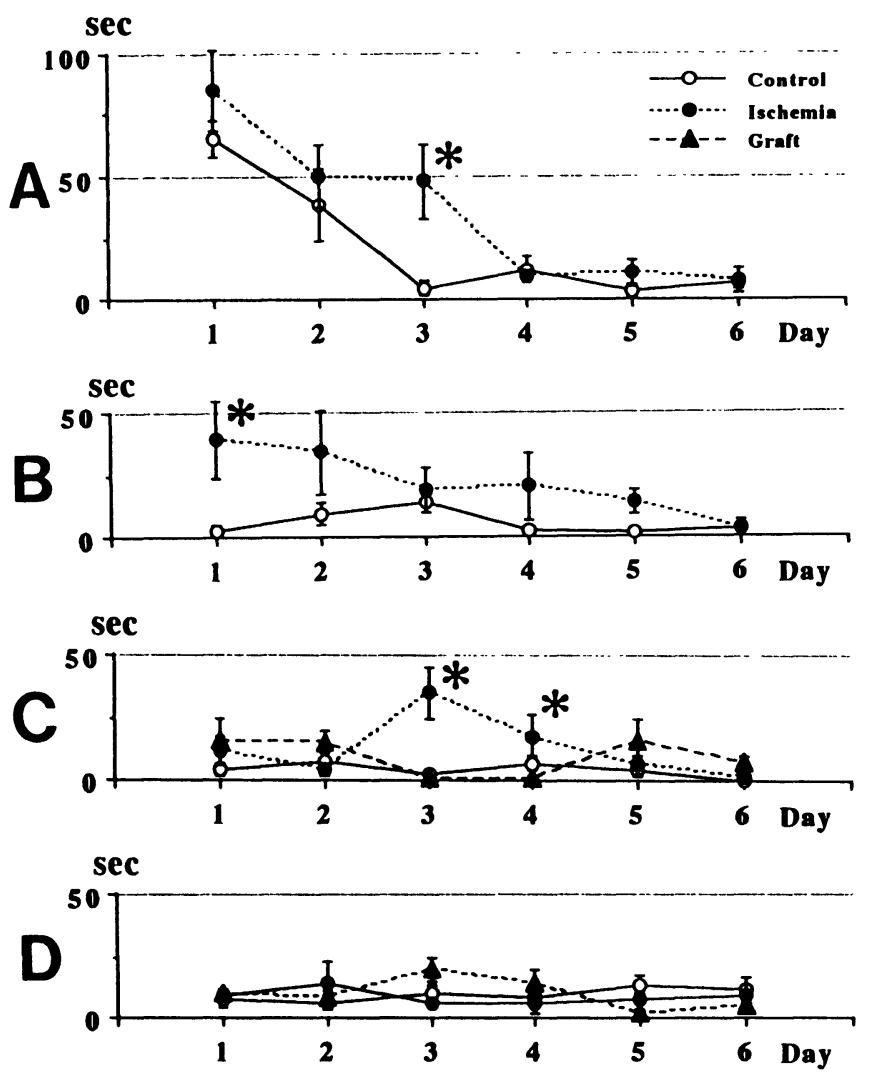

Fig. 5: Performance on four testing series of the passive avoidance task. Rats were trained in the task for 5 min each day over 6 consecutive days for each series. Ordinate: total time of ES received. Abscissa: days. $\mathbf{O}$, control rats; $\boldsymbol{O}$, ischemic rats; $\boldsymbol{\Lambda}$, grafted rats. A. The first series of tests one month after ischemia. Total time of ES decreased sharply in control $(n=6)$ but slowly in ischemic $(n=12)$. , $p<0.05$. B. The second series 2 months after ischemia. Total time of ES remained low in the control rats $(n=5)$, but increased again and did not decrease much in ischemic rats $(n=12) .^{*}, \mathrm{p}<0.05$. C. The third series 3 months after the ischemia and 1 month after the graft. Total time of ES was low and stable in control $(n=5)$ and grafted rats $(n=4)$, but unstable in ischemic rats $(n=4) .{ }^{*}, p<0.05$. D. The fourth series 6 months after the ischemia and 4 months after the graft. Total time of ES was low and stable in all groups $(n=4)$.

factor ANOVA for one repeated measure, main effects), the decrease in total time of ES was slower in the early half of the session in ischemic rats (one factor ANOVA treatment, Fisher PLSD 39.02, $\mathrm{p}<0.05$ for day 3) (Fig. 5A). On the first day of the second series of training ( 2 months after the ischemia with one month inter-test interval) the total time of ES was still low in the control rats, while in ischemic rats it was higher and again did not decrease rapidly with repeated training (Fig. $5 B)$.

In the third series of tests at 3 months after ischemia, the total time of ES in ischemic rats was still unstable. ES durations were low during the first 2 days, but increased during days 3 and 4 and decreased subsequently (one factor ANOVA treatment, $\mathrm{p}<0.05$ at day 3 between ischemic and control/grafted, Fisher PLSD 17.299, 18.235 respectively, and at day 4 between ischemic and grafted, Fisher PLSD 16.298). In grafted rats the total time of ES remained low. Control rats maintained their performance levels and received few ES. In the fourth series of training (6 months after the ischemia and 4 months after the graft), the total time of ES was low in all 3 groups.

\section{Extracellular GABA level}

Microdialysis was performed at 2 to 4 months after the ischemia or graft. The content of GABA in the dialysate of control rats (basal level) was 2.1 $\pm 1.2 \mathrm{pmol} / 30 \mu \mathrm{l}$. GABA concentrations were significantly lower $(1.0 \pm 0.5 \mathrm{pmol} / 30 \mu \mathrm{l})$ in ischemic rats at 2 to 4 months after the ischemia ( $p<0.05$, Mann-Whitney U-test) (Fig. 6). However, the content of GABA became comparable to controls $(1.8 \pm 1.0 \mathrm{pmol} / 30 \mu \mathrm{l})$ at 4 months after grafting. Consequently, the difference in GABA levels between ischemic and grafted rats became significant $(p<0.05$, Mann-Whitney U-test). The response of GABA to addition of nipecotic acid (a GABA uptake blocker) in the perfusion was also investigated. In control rats GABA level increased to $11.7 \pm 4.1 \mathrm{pmol} / 30 \mu \mathrm{l}, 5$ to 6 times the basal level. The GABA level increased also in ischemic rats $(4.1 \pm 1.5 \mathrm{pmol} / 30 \mu \mathrm{l})$ but the increase was less than $50 \%$ of the increase in the controls $(p<0.01$, Mann-Whitney U-test). In grafted rats, however, the level of GABA increased moderately, to $8.1 \pm$ $3.6 \mathrm{pmol} / 30 \mu \mathrm{l}$, which represented about a 4 -fold increase above basal levels. The absolute amount 
of increase in grafted rats was significantly greater than that seen in the ischemic rats $(p<0.05$, MannWhitney U-test) (Fig. 6).

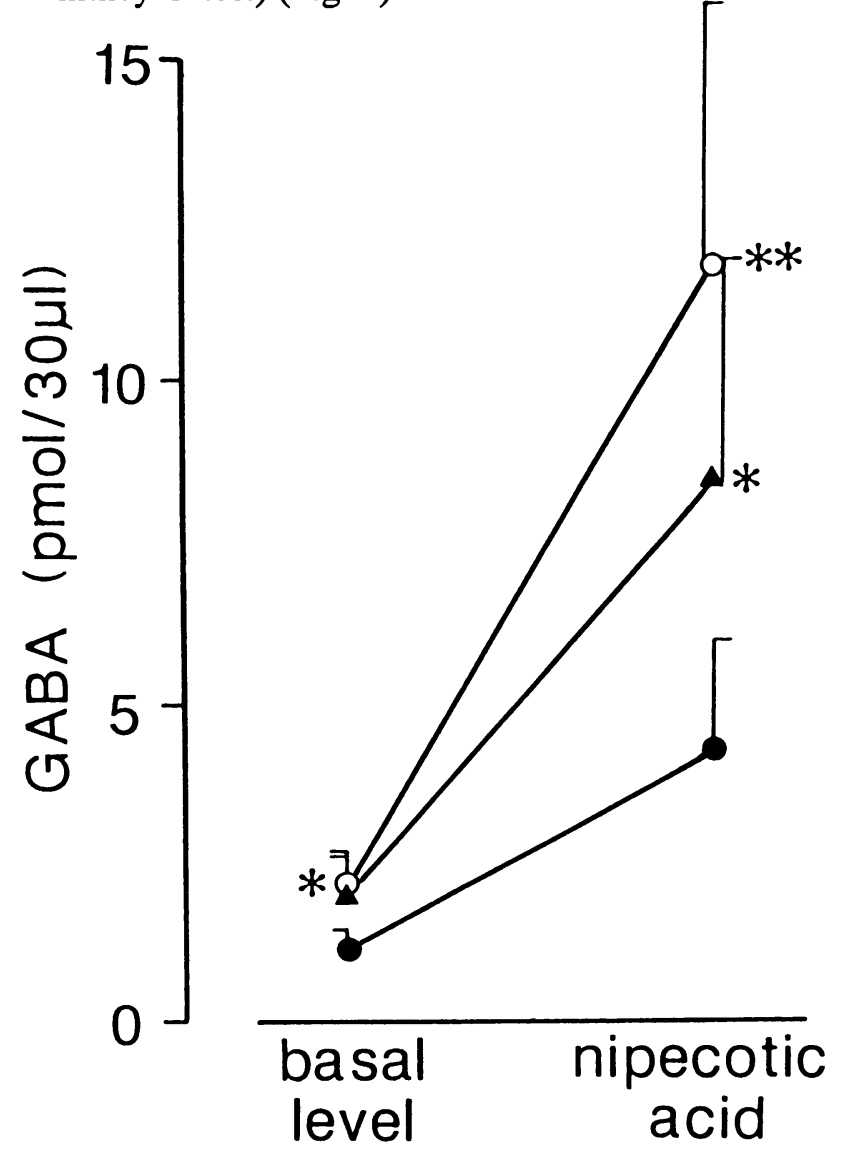

Fig. 6: Pallidal GABA levels and response to nipecotic acid. Concentrations of GABA in dialysates were measured by HPLC after treatment with OPA and expressed in pmol/30 $\mu$ l. Basal level of GABA was $2.1 \pm 1.2 \mathrm{pmol} / 30 \mu \mathrm{l}, 1.0 \pm 0.5 \mathrm{pmol} / 30 \mu \mathrm{l}$ and 1.8 $\pm 1.0 \mathrm{pmol}$ in control $(0)$, ischemic $(0)$ and grafted rats $(\boldsymbol{\Lambda})$, respectively ( $\mathrm{n}=4$ in all groups). ${ }^{*}, \mathrm{p}<0.05$ between ischemic and control/grafted groups (Mann-Whitney U-test). After treatment with nipecotic acid, GABA increased up to $11.7 \pm 4.1$ $\mathrm{pmol} / 30 \mu \mathrm{l}, 4.1 \pm 1.5 \mathrm{pmol} / 30 \mu \mathrm{l}$ and $8.1 \pm 3.6$ $\mathrm{pmol} / 30 \mu \mathrm{l}$, respectively. **, $\mathrm{p}<0.01$ between control and ischemic groups; *, p<0.05 between grafted and ischemic groups (Mann-Whitney Utest).

\section{Histology}

The size and the extent of the ischemic infarcts were variable. The largest extended over the whole striatum, pallidum and adjacent cortex. However, in the majority of the animals, the infarcts were localized in the lateral striatum and adjacent cortex (Fig. 7A). The hippocampus remained intact. In all rats the grafts survived but their sizes and locations were variable. In most cases grafts survived in the lateral striatum and adjacent cortex (Fig. 7B). Although the graft tissue appeared to be attached to the host brain, the patchy organization (cell compartments and myelinated fiber bundles) that is typical in the normal striatum was not evident inside the grafts.
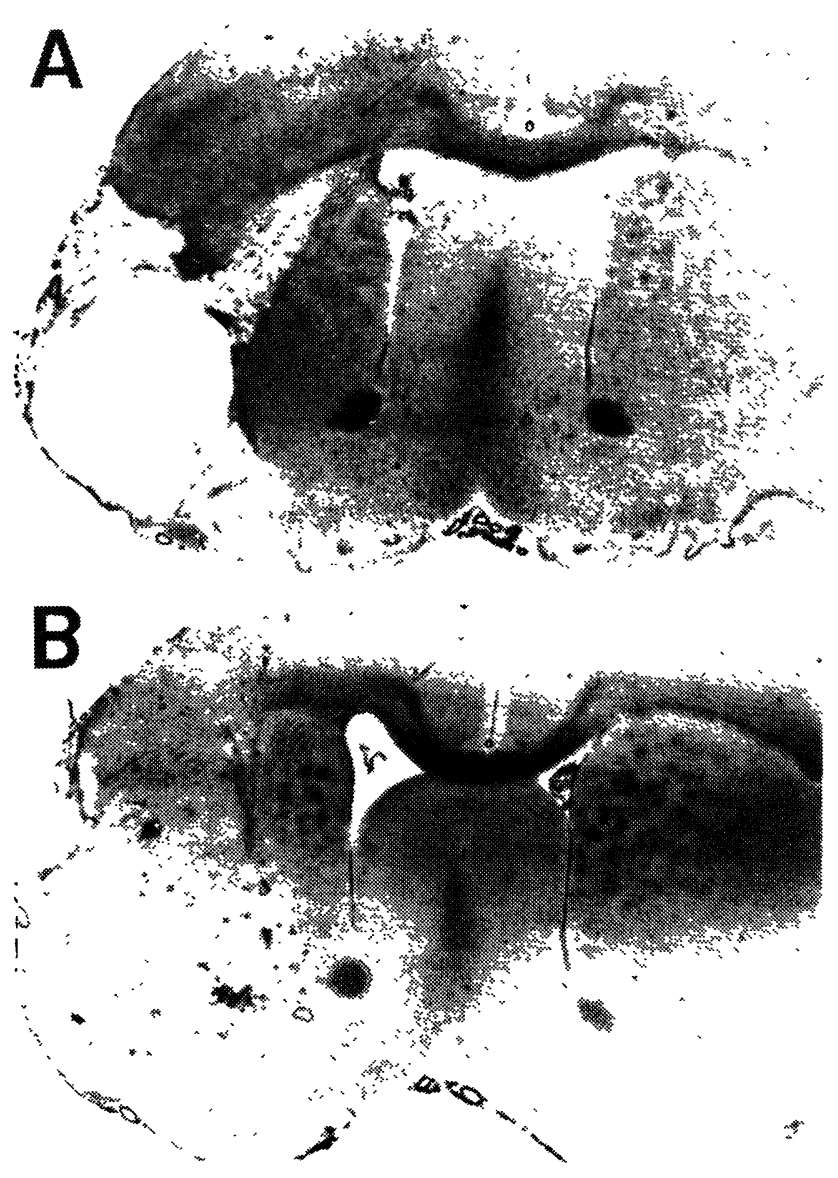

Fig. 7: Photographs of cresyl violet stained sections from an ischemic (A) and a grafted (B) animal. 


\section{DISCUSSION}

In the present study, we first made a transient occlusion in the MCA to induce infarcts in the striatum. Behavioral and biochemical deficits were assessed, and the possibility of reconstruction by neural grafting was investigated.

By one hour after intraluminal occlusion of the MCA, ischemic infarcts were induced $77,10 /$. Although the procedure was controlled as carefully as possible, there was considerable variation in the size and location of the infarcts. In the majority of animals the infarcts were located in the lateral part of the striatum and the adjacent cortex, and the hippocampus remained intact. The difference in the size and location of the infarcts may be due to the differences in the fit of the plug to the vessel, the extent of vascular collaterals, the sensitivity to ischemia, or other factors.

During ischemia all rats exhibited contralateral hemiparesis and rotation, but these disappeared within a period of days after recirculation. If the MCA is occluded permanently, severe motor disturbances appear and never spontaneously recover. In a preliminary study, the survival of rats after permanent ischemia was poor.

Although the gross motor disturbances disappeared, deficits in passive avoidance tests were relatively long-lasting. This is reasonable since the striatum receives afferent inputs from various cortical areas, and integrates and regulates these input signals. Thus, sensory/motor integration and learning are important functions of the striatum 114/. A passive avoidance task requires sensory/motor integration as well as memory function. By testing the performance of the task several times with a long inter-test interval, the retention as well as acquisition in the learning process could be investigated. In the present study the effects of ischemic infarct were evaluated in terms of performance in a passive avoidance test and by extracellular GABA content.

Control rats learned the passive avoidance task well. The total time of ES decreased day by day with consecutive training sessions and finally reached a low level. It remained low in all later trials. This indicates that retention as well as acquisition was excellent in control rats. Ischemic rats showed deficits both in acquisition and retention in the first three series of the test. In grafted rats, the deficits tended to be improved. At the fourth test (6 months after ischemia and 4 months after the graft), all groups of rats avoided the ES well. These data suggest that fetal striatal cell grafts in infarcted striatum may facilitate the improvement of deficits in a passive avoidance task. In the present study, however, the control and ischemic rats did not receive tissue transplantation, and thus it remains a possibility that a non-specific lesion or inflammatory reaction in the grafted animals could have contributed to the effects.

Striatal lesions following an excitotoxic amino acid injection have been reported to induce hyperactivity $/ 2,3 /$. In the present study some ischemic animals were slightly hyperactive and stepped down from the platform frequently. Nonetheless, in most cases we did not find significant differences in the general activity and circadian actograms between ischemic and control groups. This finding may be due to relatively smaller lesions that were localized to the lateral part of the striatum unilaterally. The hyperactive rats had a tendency to have more trouble in learning than the ischemic non-hyperactive rats. However, a final conclusion should be postponed as the number in the sample was small.

When the lateral half of the striatum is lesioned, the inputs from the cortex as well as the outputs to the pallidum and other structures are disturbed $/ 12 /$. When the lateral cortex adjacent to the striatum is further damaged by the ischemic infarct, some portions of the corticostriatal pathway could be destroyed. This may be the basis of the poor performance in the passive avoidance task observed in the present study.

The size of the graft mass grown in the striatum was also variable. To obtain data for better matching the size of the graft (the number of cells transplanted) with the degree of striatal damage in future experiments, the extent and location of the infarct were determined noninvasively by MRI before grafting.

After the ischemic infarct, the pallidal GABA level decreased to about half that of controls $/ 11 /$. GABA recovered to nearly control levels following transplantation, and was further increased by treatment with nipecotic acid, a GABA uptake 
blocker $/ 5 /$, in the perfusion medium. The basal level of GABA and the level after treatment with nipecotic acid were significantly greater in grafted rats than in ischemic rats. It is possible that functional GABAergic transmission was partially restored, since the release and uptake of GABA could be manipulated by a pharmacological challenge.

The striatal histological image, patchy organization of cells and bundles, was not found in the grafts, suggesting that the interconnection between the host and the graft was not complete /6/. Further analyses using other tracing methods are necessary to better understand their connection $/ 18,21 /$.

In summary, fetal striatal cell grafts into the infarcted striatum of the rat partially improved pallidal GABA release and may have facilitated the improvement of deficits in a passive avoidance task. Neural grafting might be a useful approach in the treatment of ischemic infarcts.

\section{ACKNOWLEDGEMENTS}

This work was entrusted to Nagoya City University Medical School by the Science and Technology Agency, using the Special Coordination Funds for promoting Science and Technology. This work was supported in part by the Ministry of Education, Science and Culture, Grant-in-Aid for Scientific Research 03454133 and for Developmental Scientific Research 04557005, and also by a grant from the DAIKOU Foundation.

\section{REFERENCES}

1. Björklund A, Stenevi U. Reconstruction of the nigrostriatal dopamine pathway by intracerebral nigral transplants. Brain Res 1979; 177: 555-560.

2. Deckel AW, Moran TH, Coyle J, Sanberg P, Robinson RG. Anatomical predictors of behavior recovery following fetal striatal transplants. Brain Res 1986; 365: $249-258$.

3. Isacson O, Dunnett SB, Björklund A. Graft-induced behavioral recovery in an animal model of Huntington disease. Proc Natl Acad Sci USA 1986; 83: 2728-2732.

4. Jarrett HW, Cooksy KD, Ellis B, Anderson JM. The separation of O-opthalaldehyde derivatives of amino acid by reverse phase chromatography on octylsilica columns. Analyt Biochem 1986; 153: 189-198.
5. Kehr J, Ungerstedt U. Fast HPLC estimation of $\gamma$ aminobutylic acid in microdialysis perfusate: Effect of nipecotic and 3-mercaptopropionic acids. J Neurochem 1988; 51: 1308-1310.

6. Koide $\mathrm{K}$, Hashitani T, Aihara N, Mabe H, Nishino $\mathrm{H}$. Improvement of passive avoidance task after grafting of fetal striatal cell suspensions in ischemic striatum in the rat. Restr Neurol Neurosci, in press.

7. Koizumi J, Yoshida Y, Nakazawa T, Ooneda G. Experimental studies of ischemic brain edema. 1. A new experimental model of cerebral embolism in rats in which recirculation can be introduced in the ischemic area. Jpn J Stroke 1986; 8: 1-8.

8. Mampalam TJ, Gonzalez MF, Weinstein P, Sharp FR. Neuronal changes in fetal cortex transplanted to ischemic adult cortex. J Neurosurg 1988; 69: 904-912.

9. Mudrick LA, Leug PPH, Baimbridge KG, Miller JJ. Neuronal transplants used in the repair of acute ischemic injury in the central nervous system. In: Gash DM, Sladek JR Jr, eds, Progress Brain Res Vol 78. Amsterdam: Elesevier, 1988; 87-93.

10. Nagasawa $H$, Kogure $K$. Correlation between cerebral blood flow and histologic changes in a new rat model of middle cerebral occlusion. Stroke 1989; 20: 1037 . 1043.

11. Nakayama H. Regional and time-sequential changes of amino acid neurotransmitters after focal cerebral ischemia in the rat. Neurol Surg 1986; 38: 1043-1050.

12. Nauta HJW. A proposed conceptual reorganization of the basal ganglia and telencephalon. Neuroscience 1979; 4: 1875-1881.

13. Nishino $H$, Hashitani $T$, Kumazaki $M$, Sato $H$, Furuyama F, Isobe Y, Watari N, Kanai M, Shiosaka S. Long-term survival of grafted cells, dopamine synthesis/release, synaptic connections, and functional recovery after transplantation of fetal nigral cells in rats with unilateral 6-OHDA lesions in the nigrostriatal dopamine pathway. Brain Res 1990; 534: 83-93.

14. Oberg RGE, Divac I. Cognitive functions of the neostriatum. In: Divac I, Oberg RGE, eds, The Neostriatum. Oxford: Pergamon Press 1979: 291-313.

15. Onifer SM, Low WC. Spatial memory deficit resulting from ischemia-induced damage to the hippocampus is ameliorated by intra-hippocampal transplants of fetal hippocampal neurons. In: Dunnett SB, Richards SJ, eds, Progress Brain Res Vol 82. Amsterdam: Elsevier, 1990; 359-366.

16. Perlow MJ, Freed WJ, Hoffer BJ, Seiger A, Olson L, Wyatt RJ. Brain grafts reduce motor abnormalities produced by destruction of nigrostriatal dopamine system. Science 1979; 204: 643-647.

17. Polezhaev LV, Alexandrova MA. Transplantation of embryonic brain tissue into the brain of adult rats after hypoxic hypoxia. J Hirnforsh 1984; 25: 99-106.

18. Pritzel $M$, Isacson $O$, Brundin $P$, Wiklund $L$, Björklund A. Afferent and efferent connections of striatal grafts implanted into the ibotenic acid lesioned neostriatum in 
adult rats. Exp Brain Res 1986; 65: 112-126.

19. Pulsinelli WA, Brierley JB. A new model of bilateral hemispheric ischemia in the unanesthetized rat. Stroke 1979; 10: 267-271.

20. Sirinathsinghji DJS, Dunnett SB, Isacson O, Clarke DJ, Kendrick K, Björklund A. Striatal grafts in rats with unilateral neostriatal lesion-II. In vivo monitoring of GABA release in globus pallidus and substantia nigra. Neuroscience 1988; 24: 803-811.

21. Wictorin K, Simerly RB, Isacson O, Swanson LW,
Björklund A. Connectivity of striatal grafts implanted into the ibotenic acid-lesioned striatum. III. Efferent projecting graft neurons and their relation to host afferents within the grafts. Neuroscience 1989; 30: 313-330.

22. Yamamoto M, Tamura A, Kirino T, Shimizu M, Sano $\mathrm{K}$. Behavioral changes after focal cerebral ischemia by left middle cerebral artery occlusion in rats. Brain Res 1988; 452: 323-328. 

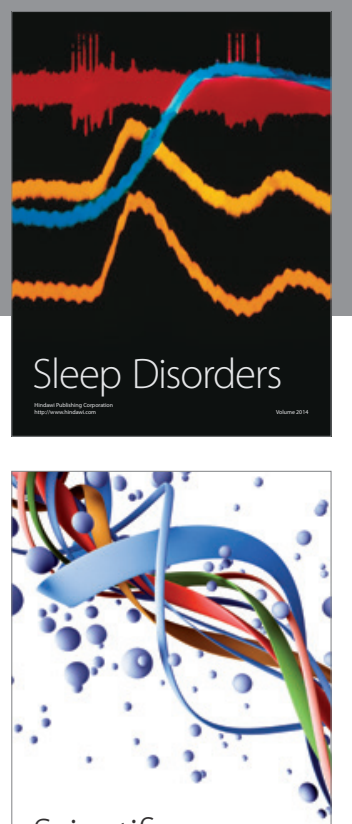

Scientifica
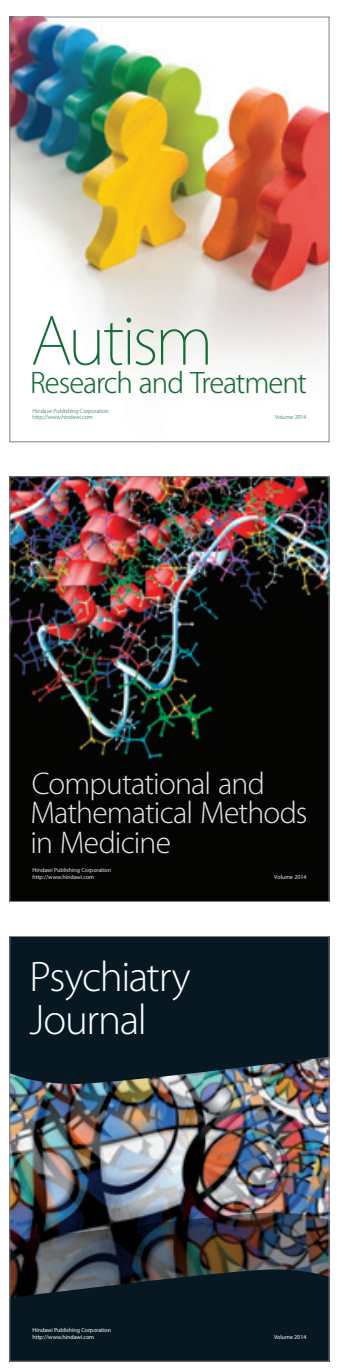
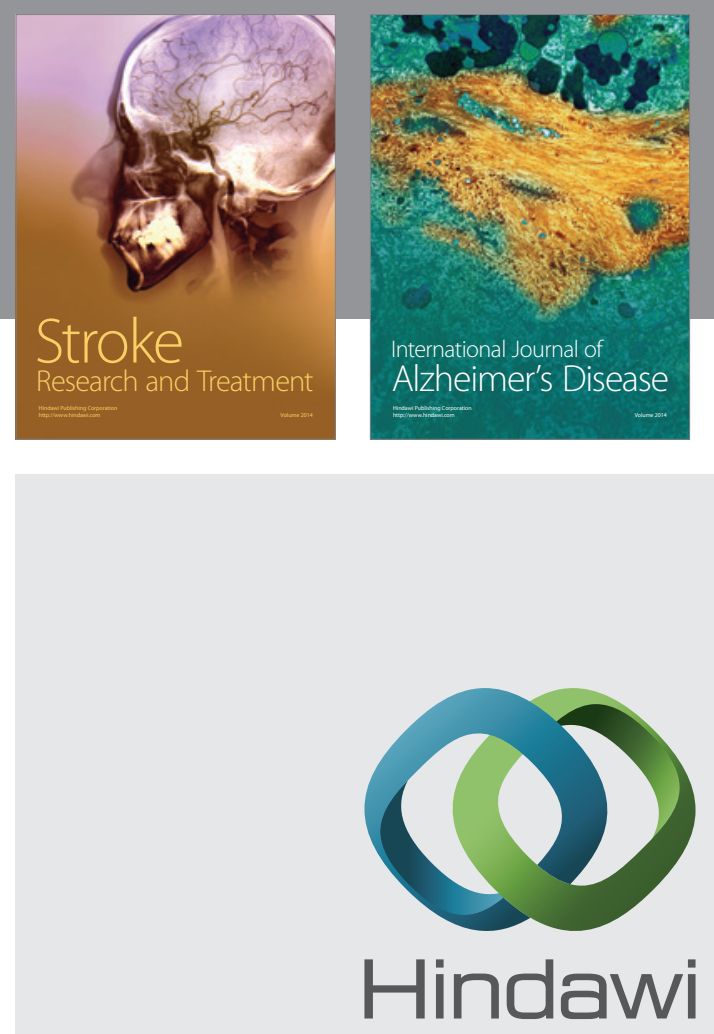

Submit your manuscripts at

http://www.hindawi.com
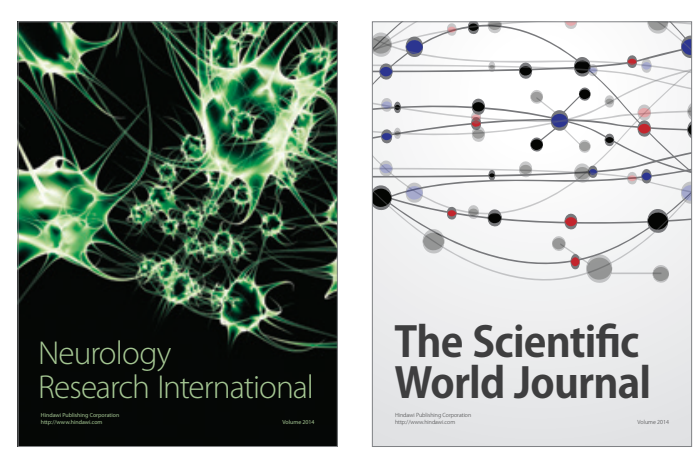

The Scientific World Journal

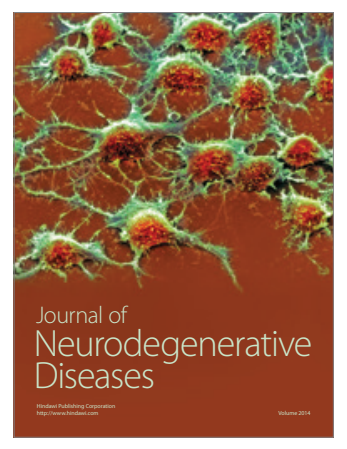

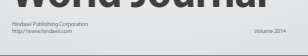

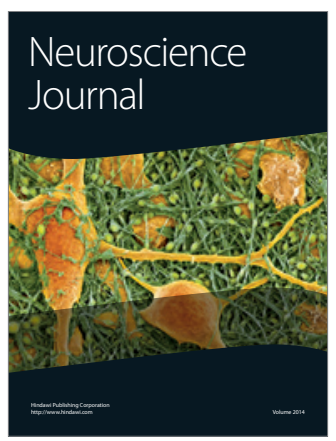

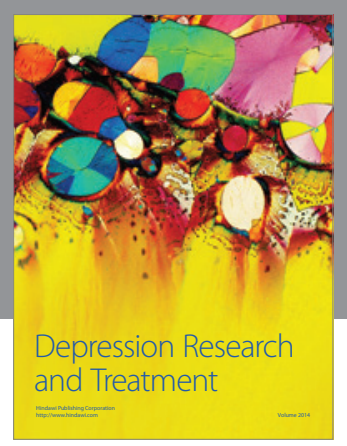
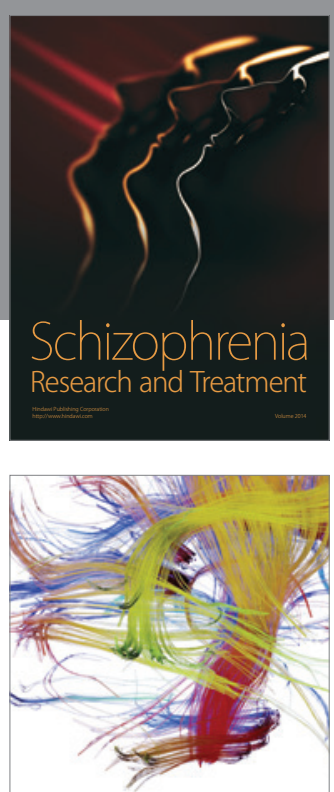

Brain Science

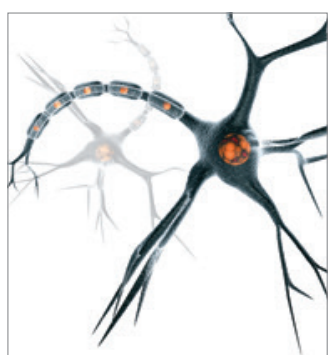

Neural Plasticity
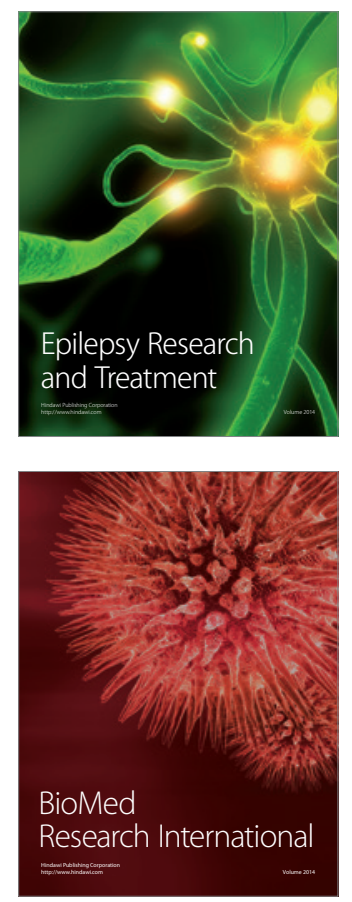

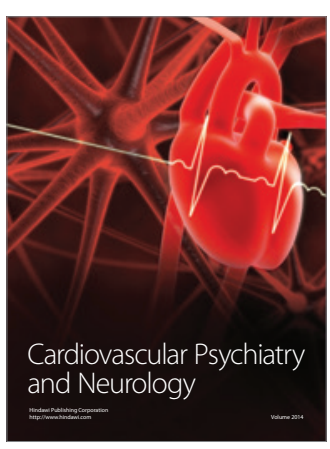

Parkinson's

Disease
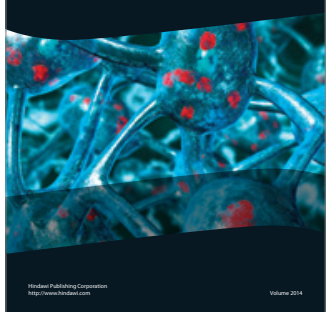